\title{
Improved performance due to dietary supplementation with selected herbal extracts of broiler chickens infected with Eimeria spp.
}

\author{
A. Arczewska-Włosek ${ }^{1}$ and S. Świątkiewicz \\ National Research Institute of Animal Production, Department of Animal Nutrition and Feed Science \\ Krakowska 1, 32-083 Balice, Poland
}

KEY WORDS: broiler chickens, coccidiosis, herbal extracts, performance

Received: 16 October 2012

Revised: 27 May 2013

Accepted: 2 September 2013
${ }^{1}$ Corresponding author: e-mail: anna.arczewska@izoo.krakow.pl

\begin{abstract}
The aim of the study was to investigate the effect of dietary herbal extracts derived from garlic (Allium sativum), rosemary (Rosmarinus officinalis), sage (Salvia officinalis), oregano (Origanum vulgare), nettle (Urtica dioica), purple coneflower (Echinacea purpurea), or thyme (Thymus vulgaris) on the performance indices and oocyst output in broilers experimentally infected with 190000 oocysts of Eimeria spp. on day 12 of age. A total of 400 one-day-old Ross 308 broiler chicks was randomly allocated into 10 groups with 5 replicates (cages) of 8 chickens per replicate. Two of the groups, one challenged and the other not, were given a basal maize-soyabean meal diet without any additives; one of the challenged groups was administered a basal diet with the coccidiostat diclazuril $\left(1 \mathrm{mg} \cdot \mathrm{kg}^{-1}\right)$ and the remaining birds of the infected groups were given a diet supplemented with one of the tested herbal extracts at a level of $750 \mathrm{mg} \cdot \mathrm{kg}^{-1}$. Throughout the 42 days of the experiment, performance parameters, mortality, oocyst output, and slaughter indices were recorded. Among the tested herbal extracts, in the first rearing period ( $9 \mathrm{~d}$ post infection), only garlic and sage extracts alleviated the negative effect of infection, as shown by the increase in body weight gain to the level recorded in the coccidiostat-supplemented group and, in the case of garlic extract, by lower mortality. In the second and entire experimental period, dietary supplementation with the herbal extracts improved the growth performance of infected chickens to the level obtained in the groups infected and fed the coccidiostat or the uninfected and unsupplemented ones, but there was no positive effect of extracts on oocyst output. It is concluded that the herbal extracts tested in the current study do not prevent coccidiosis induced by high-pathogenic field Eimeria spp., although they have a beneficial effect on recovery after infection, which was expressed by the favourable impact on compensatory growth and, thus, on the final performance indices.
\end{abstract}

\section{Introduction}

Coccidiosis is an intestinal parasitism common in intensively producing poultry. It is caused by protozoa of the genus Eimeria that have a short and direct life cycle. Infection occurs by ingestion of sporulated oocysts that are common in poultry environments. Due to the faecal-oral route of oocyst transmission, coccidiosis is a major problem in high-density poultry production and it is extremely rare to find a commercial chicken flock free of coccidia(Williams, 2002,2005). The parasites multiply in the intestinal cells and cause tissue damage resulting in lowered feed intake and body 
weight gain, malabsorption of nutrients, diarrhoea, inflammation, morbidity or even death, depending on the degree of pathogenicity of the infection (Williams, 2002). Moreover, coccidiosis makes birds more susceptible to secondary bacterial infections and necrotic enteritis induced by Clostridium perfringens (Williams, 2005; Persia et al., 2006).

In the poultry industry, control of coccidiosis is based mainly on feed coccidiostats and, to a lesser extent, vaccination. It is believed that the effectiveness of coccidiostats was the main factor allowing the development of the poultry industry, but their widespread use and misuse have led to the emergence of drug resistance of Eimeria strains against most of the available anticoccidials (Chapman, 1997; Williams, 2002). Moreover, there is strong evidence that residues of some coccidiostats may be present in meat and the consumer is not being given adequate protection against this (Olejnik et al., 2009). The increasing drug resistance of coccidia, the risk of accumulation of coccidiostat residues in meat and their potential negative impact on human health, consumer pressure in respect to naturally-raised chickens, and the risk of potential cross-resistance of microorganisms to the antimicrobials used to treat humans or animals gave rise to Regulation (EC) No. 1831/2003 of the European Parliament and Council which contains information on the intention to ban the prophylactic use of coccidiostats (Anonymous, 2003). Consequently, the importance of new alternative approaches for control of coccidiosis is strongly emphasized. Despite natural substitutes for coccidiostats being the subject of many studies, according to the report on the withdrawal of coccidiostats and histomonostats from use in feed additives submitted by the European Commission (Anonymous, 2008), there is currently no comparably effective alternative to coccidiostats. There is thus the need to continue the studies. Due to their natural origin, lack of a grace period, wide dosage range, and many qualities such antimicrobial, antioxidant, antiviral, antihelminthic, anti-stress properties, effects like gut microflora manipulation, stimulation of appetite, feed intake and secretion of endogenous digestive enzymes, immune enhancement, and nutrigenomic activity, plant extracts are considered factors that can support both the performance and health status of animals (Hashemi and Davoodi, 2011; Rahimi et al., 2011). Within this context many plants and herbal compounds are being studied for the control of coccidiosis (Youn and Noh, 2001; Naidoo et al., 2008; Chandrakesan et al., 2009; Abbas et al., 2010; Lee et al., 2010; Haq et al., 2011).
The current study is in keeping with the trend to develop natural methods of coccidiosis prophylaxis and the aim of this experiment was to investigate the effects of dry herbal extracts derived from garlic (Allium sativum), rosemary (Rosmarinus officinalis), sage (Salvia officinalis), oregano (Origanum vulgare), nettle (Urtica dioica), purple coneflower (Echinacea purpurea), and thyme (Thymus vulgaris) on the performance indices and oocyst output in broilers experimentally infected with Eimeria spp.

\section{Material and methods}

All of the experimental procedures involving animals were approved by the Local Animal Care and Use Committee.

A total of 400 one-day-old Ross 308 broiler chicks was randomly allocated to 10 groups with 5 replicates (cages) of 8 chickens per replicate (4 male and 4 female). The chickens were reared to 42 days of age in wire-floored cages with free access to water and feed. All of the birds were fed with a starter ( 1 to $21 \mathrm{~d}$ ) and grower-finisher ( 22 to 42 d) maize-soyabean meal basal diet, free of coccidiostats and formulated to meet or exceed the nutrient requirements of broilers (Smulikowska and Rutkowski, 2005). The basal diets contained, as calculated on the basis of chemical analysis, $\%$ : crude protein 22, Lys 1.23 , Met 0.56 , Ca 0.95 , and available $\mathrm{P} 0.44, \mathrm{ME} \cdot \mathrm{kg}^{-1} 12.4 \mathrm{MJ}$ (starter) or, crude protein 20, Lys 1.18, Met 0.51 , Ca 0.93 , and available P $0.41, \mathrm{ME} \cdot \mathrm{kg}^{-1} 13 \mathrm{MJ}$ (grower-finisher). At $12 \mathrm{~d}$ of age birds from groups $2-10$ were inoculated per os with a total of 190000 sporulated oocysts of a mixture of E. acervulina, E. tenella, $E$. maxima and E. necatrix originating from field isolates, while chickens from group 1 were orally inoculated with sterile water. The experimental design included two negative control groups fed diets without feed additives: unsupplemented-uninfected (UU, 1) and unsupplemented-infected (UI, 2), and a positive control group (3) fed a diet with the addition of a coccidiostat, diclazuril, at a level of $1 \mathrm{mg} \cdot \mathrm{kg}^{-1}$ feed. The experimental dietary treatments in groups 4-10 were formulated by supplementing the basal diet with the dried alcoholic herbal extract with maltodextrin as the carrier, at a level of 750 $\mathrm{mg}$ of extract $\cdot \mathrm{kg}^{-1}$ feed derived from, respectively, garlic (Allium sativum), rosemary (Rosmarinus officinalis), sage (Salvia officinalis), oregano (Origanum vulgare), nettle (Urtica dioica), purple coneflower (Echinacea purpurea), or thyme (Thymus vulgaris). The total content of phenolic compounds, expressed as caffeic acid, in particular extracts before 
application to the maltodextrin carrier, was respectively (mg $\cdot 100 \mathrm{~g}^{-1} \pm$ standard deviation): $380.42 \pm$ $3.14 ; 402.42 \pm 8.67 ; 660.66 \pm 4.21 ; 984.43 \pm 44.72$; $70.18 \pm 3.14 ; 256.52 \pm 6.98 ; 486.56 \pm 8.79$.

The birds were weighed at 1,21 and $42 \mathrm{~d}$ of age. Body weight gain (BWG), feed intake (FI), feed conversion ratio (FCR) and mortality were calculated for days 1-21, 22-42 and 1-42 of age. The number of oocysts per gram of excreta (OPG) was determined using a McMaster chamber (Mazurkiewicz, 2005) in pooled excreta samples taken from each replicate on post-inoculation days 7, 14, 21 and 28 .

At the end of the experiment and after $12 \mathrm{~h}$ feed withdrawal, all of the chickens were weighed and 4 representative male and 4 female chickens with live body weights close to the group average were chosen from each group, marked with number signs and decapitated. Chickens were plucked, the intestines and crop were removed and carcasses stored overnight in $4^{\circ} \mathrm{C}$. The mass of the cooled carcass with edible giblets (gizzard, liver) was estimated and carcass yield calculated. The breast muscles, abdominal fat, livers and gizzards were excised and weighed. The breast muscle and abdominal fat contents were expressed as a percentage of cold carcass. The weights of the liver and gizzard were expressed as percentage of live- weight (Ziołecki and Doruchowski, 1989).

The data were analysed by means of one-way ANOVA and the significance of differences between mean values was assessed using Duncan's test (SAS Enterprise Guide 4.3). Differences were considered significant at a probability level of $p<0.05$.

\section{Results}

The performance data obtained from the trial are presented in Table 1. The mixed inoculum of field Eimeria spp. was found to be very pathogenic. Evident symptoms of severe coccidiosis such as bloody diarrhoea, closed eyes, depression, ruffled feathers, inappetance, and variable levels of mortality were observed in all infected groups. The performance data obtained in the starter period (Table 1) also confirmed the severe course of coccidiosis after experimental challenge, which significantly negatively affected BWG, FI and FCR at $21 \mathrm{~d}$ of age ( 9 days after challenge, groups $2-10$ vs 1 ). The average BWG and FI obtained in the group of infected chickens fed the unsupplemented diet were, respectively, $36 \%$ and $20 \%$ lower and FCR was $20 \%$ higher in comparison with the uninfected ones (group 2 vs 1). Among the infected chickens, only addition of the coccidiostat (group 3) led to avoiding mortality and significantly alleviated the deleterious effect of infection on performance in the first rearing phase. BWG and FCR obtained in this group, however worse than in UU (group 1), were 21\% and 9.5\% more favourable compared with UI (group 2), respectively. Administration of the herbal extract derived from garlic (group 4) and sage (group 6) resulted in an increase of BWG to the level recorded in the coccidiostat-supplemented group. Furthermore, addition of garlic extract to the diet of infected chickens resulted in a FCR comparable to that recorded in the coccidiostat-treated group and in the lowest mortality rate among all infected groups.

In the second feeding phase (22-42 $\mathrm{d}$ of age), the addition of all herbal extracts (groups 4-10) increased $(p<0.05)$ the BWG of infected chickens to the level obtained in the coccidiostat-supplemented (3) and uninfected and unsupplemented (1) groups. Numerically, the largest increase in BWG was shown in the sage- (group 6) and purple coneflower (group 9) supplemented groups, and the difference in respect to UI was, respectively, $21 \%$ and $18.5 \%$. The worst BWG, though comparable to UU, was found in the group of infected and unsupplemented chickens $(p<0.05)$. No significant differences in FI and FCR were observed. A relatively high mortality rate was recorded in groups UU, UI and infected and coccidiostat-supplemented (3), equalling respectively, $10 \%, 15 \%$ and $15 \%$. In the groups of infected chickens fed a diet with addition of garlic (4), oregano (7), nettle (8), or thyme (10) extracts, no mortality was noted.

Analysis of performance results for the entire experimental period revealed the adverse effect on the growth of chickens caused by infection (group 2 vs 1 ). Despite the lack of significant differences in feed intake, infected chickens fed a diet with no additive were characterized by decreased BWG $(p<0.05)$, numerically the worst FCR $(p>0.05)$, and the highest mortality rate $(25 \%)$ among all groups. Incorporation of any of the herbal extracts into the diets of infected chickens resulted in performance indices comparable to those obtained in coccidiostat-supplemented (3) and uninfected (1) groups. Moreover, garlic extract led to a two-fold decrease in the mortality rate in comparison with the uninfected group (group 4 vs 1).

The results of the slaughter analysis showed no differences among the experimental groups in respect to the analysed parameters (Table 2). 
Table 1. Effect of experimental treatments on performance of broiler chickens

\begin{tabular}{|c|c|c|c|c|c|c|c|c|c|c|c|}
\hline \multirow[b]{2}{*}{ Indices } & \multicolumn{10}{|c|}{ Dietary treatment, group No. } & \multirow{3}{*}{$\mathrm{SEM}^{3}$} \\
\hline & $\overline{-}$ & $\overline{2}$ & $\begin{array}{l}\text { diclazuril }^{1} \\
3\end{array}$ & $\begin{array}{l}\text { garlic } 2 \\
4\end{array}$ & $\begin{array}{l}\text { rosemary }{ }^{2} \\
5\end{array}$ & $\begin{array}{l}\text { sage }^{2} \\
6\end{array}$ & $\begin{array}{l}\text { oregano }{ }^{2} \\
7\end{array}$ & $\begin{array}{l}\text { nettle }{ }^{2} \\
8\end{array}$ & $\begin{array}{l}\text { purple } \\
\text { coneflower }^{2} 9\end{array}$ & $\begin{array}{l}\text { thyme }{ }^{2} \\
10\end{array}$ & \\
\hline Challenge $^{4}$ & - & + & + & + & + & + & + & + & + & + & \\
\hline \multicolumn{12}{|l|}{ Days 1-21 } \\
\hline BWG, $g$ & $621^{a}$ & $396^{\mathrm{cd}}$ & $480^{b}$ & $432^{\text {bcd }}$ & $380^{d}$ & $445^{\mathrm{bc}}$ & $419^{c d}$ & $421^{\mathrm{cd}}$ & $394^{\text {cd }}$ & $424^{\text {cd }}$ & 10.6 \\
\hline $\mathrm{Fl}, \mathrm{g}$ & $991^{a}$ & $789^{c}$ & $868^{\mathrm{bc}}$ & $843^{\mathrm{bc}}$ & $814^{\mathrm{bc}}$ & $887^{b}$ & $832^{\mathrm{bc}}$ & $853^{\mathrm{bc}}$ & $840^{\mathrm{bc}}$ & $867^{\mathrm{bc}}$ & 10.9 \\
\hline $\begin{array}{l}\text { FCR, } g \text { feed } \cdot g^{-1} \\
\text { BWG }\end{array}$ & \multirow{2}{*}{\multicolumn{11}{|c|}{$\begin{array}{ll}2.00^{\mathrm{ab}} & \\
10 & 10\end{array}$}} \\
\hline mortality, $\%$ & & & & & & & & & & & \\
\hline \multicolumn{12}{|l|}{ Days 22-42 } \\
\hline BWG, g & $1466^{\mathrm{ab}}$ & $1357^{b}$ & $1567^{a}$ & $1522^{\mathrm{a}}$ & $1580^{a}$ & $1639^{a}$ & $1577^{a}$ & $1577^{a}$ & $1608^{a}$ & $1549^{a}$ & 18.7 \\
\hline $\mathrm{Fl}, \mathrm{g}$ & 2814 & 2933 & 2961 & 2729 & 2807 & 3148 & 2859 & 2875 & 2906 & 2838 & 44.4 \\
\hline $\begin{array}{l}\text { FCR, } g \text { feed.g } \\
\text { BWG }^{-1}\end{array}$ & 1.92 & 2.27 & 1.89 & 1.79 & 1.77 & 1.91 & 1.81 & 1.82 & 1.81 & 1.83 & 0.04 \\
\hline mortality, \% & 10 & 15 & 15 & 0 & 2.5 & 12.5 & 0 & 0 & 2.5 & 0 & \\
\hline \multicolumn{12}{|l|}{ Days 1-42 } \\
\hline BWG, g & $2087^{a}$ & $1753^{b}$ & $2047^{a}$ & $1955^{a}$ & $1960^{\mathrm{a}}$ & $2083^{a}$ & $1993^{a}$ & $1998^{a}$ & $2002^{a}$ & $1973^{a}$ & 20.6 \\
\hline $\mathrm{Fl}, \mathrm{g}$ & 3783 & 3692 & 3815 & 3575 & 3631 & 4000 & 3696 & 3736 & 3754 & 3709 & 44.3 \\
\hline $\begin{array}{l}\text { FCR, } g \text { feed } \cdot g^{-1} \\
\text { BWG }\end{array}$ & 1.81 & 2.15 & 1.86 & 1.83 & 1.85 & 1.91 & 1.85 & 1.87 & 1.88 & 1.88 & 0.026 \\
\hline mortality, \% & 10 & 25 & 15 & 5 & 12.5 & 22.5 & 10 & 17.5 & 10 & 12.5 & \\
\hline
\end{tabular}

a, b, c, d - means in rows with different superscripts differ significantly at $p<0.05 ;{ }^{1}$ diclazuril administered at dose of $1 \mathrm{mg} \cdot \mathrm{kg}^{-1}$ feed; ${ }^{2}$ herbal extracts administered at dose of $750 \mathrm{mg} \cdot \mathrm{kg}^{-1}$ feed; ${ }^{3} \mathrm{SEM}$ - standard errors mean; ${ }^{4}$ challenge with 190000 of sporulated oocysts of mixture of E. acervulina, E. tenella, E. maxima and E. necatrix at 12 day of age; BWG - body weight gain; FI - feed intake; FCR - feed conversion ratio

Table 2. Effect of experimental treatments on results of slaughter analysis $(n=8), p>0.05$

\begin{tabular}{|c|c|c|c|c|c|c|c|c|c|c|c|}
\hline \multirow{3}{*}{ Indices } & \multicolumn{10}{|c|}{ Dietary treatment, group No. } & \multirow{3}{*}{$\mathrm{SEM}^{3}$} \\
\hline & - & - & diclazuril $^{1}$ & garlic $^{2}$ & rosemary ${ }^{2}$ & sage $^{2}$ & oregano $^{2}$ & nettle ${ }^{2}$ & \multicolumn{2}{|c|}{ purple coneflower ${ }^{2}$ thyme ${ }^{2}$} & \\
\hline & 1 & 2 & 3 & 4 & 5 & 6 & 7 & 8 & 9 & 10 & \\
\hline Challenge $^{4}$ & - & + & + & + & + & + & + & + & + & + & \\
\hline Carcass yield, \% LBW 5 & 76.9 & 76.7 & 77.2 & 75.8 & 75.8 & 76.5 & 76.8 & 76.8 & 76.3 & 76 & 0.27 \\
\hline Breast meat yield, $\%$ carcass & 25.2 & 25 & 25.5 & 24.6 & 25.2 & 24.9 & 25.3 & 24.6 & 25 & 25.4 & 0.204 \\
\hline Abdominal fat, $\%$ carcass & 1.92 & 1.75 & 1.55 & 1.53 & 1.67 & 1.54 & 1.89 & 1.99 & 1.82 & 1.58 & 0.078 \\
\hline Liver, \% LBW 5 & 1.83 & 1.99 & 1.99 & 1.84 & 1.93 & 1.87 & 1.82 & 1.97 & 1.96 & 1.98 & 0.023 \\
\hline Gizzard, \% LBW5 & 1.3 & 1.39 & 1.42 & 1.24 & 1.31 & 1.38 & 1.28 & 1.27 & 1.44 & 1.34 & 0.021 \\
\hline
\end{tabular}

${ }^{1}$ diclazuril administered at dose of $1 \mathrm{mg} \cdot \mathrm{kg}^{-1}$ feed; ${ }^{2}$ herbal extracts administered at dose of $750 \mathrm{mg} \cdot \mathrm{kg}^{-1}$ feed; ${ }^{3} \mathrm{SEM}$ - standard error of mean; ${ }^{4}$ challenge with 190000 of sporulated oocysts of mixture of E. acervulina, E. tenella, E. maxima and E. necatrix at 12 day of age; ${ }^{5}$ LBW - live body weight

The number of oocysts per gram of excreta (OPG) confirms the high effectiveness of the experimental infection of the chickens with sporulated Eimeria oocysts (Table 3). This number remained high up to 14 days after infection in all of the infected groups. Diclazuril was the most effective in reducing OPG on day 7 post infection and the difference was statistically significant $(p<0.05)$ relative to all other groups of infected chickens. The OPG in herbal extract-supplemented groups was comparable or higher $(p<0.05)$ in comparison with the infected unsupplemented group (groups 4-10 vs 2). An enormous decrease in OPG was noted at $21 \mathrm{~d}$ post infection in all infected groups. The OPG recorded in all supplemented groups was significantly lower than in the infected unsupplemented one (groups 3-10 vs 2). Small amounts of oocysts were found in excreta samples from the uninfected birds, thus cross contamination had occurred despite a strict hygiene regime. 
Table 3. Effect of experimental treatments on oocyst counts, thous. $\mathrm{g}^{-1}$ of excreta

\begin{tabular}{|c|c|c|c|c|c|}
\hline \multirow{2}{*}{$\begin{array}{l}\text { Dietary treatment, } \\
\text { group No. }\end{array}$} & \multirow{2}{*}{ Challenge $^{4}$} & \multicolumn{4}{|c|}{ Days post infection } \\
\hline & & $\overline{7}$ & 14 & 21 & 28 \\
\hline,- 1 & - & $0^{d}$ & 0.04 & $0.12^{b}$ & 0 \\
\hline,- 2 & - & $439^{c}$ & 34.9 & $0.60^{\mathrm{a}}$ & 0.07 \\
\hline Diclazuril',3 & + & $105^{d}$ & 14.7 & $0.04^{b}$ & 0 \\
\hline Garlic $^{2}, 4$ & + & $626^{\mathrm{ab}}$ & 39.3 & $0.14^{b}$ & 0.04 \\
\hline Rosemary ${ }^{2}, 5$ & + & $752^{\mathrm{a}}$ & 42.4 & $0.20^{\mathrm{b}}$ & 0.02 \\
\hline Sage $^{2}, 6$ & + & $480^{\mathrm{bc}}$ & 45.0 & $0.06^{b}$ & 0.06 \\
\hline Oregano $^{2}, 7$ & + & $446^{c}$ & 27.3 & $0.02^{\mathrm{b}}$ & 0 \\
\hline Nettle $^{2}, 8$ & + & $583^{b c}$ & 60.6 & $0.24^{b}$ & 0.06 \\
\hline Purple coneflower ${ }^{2}, 9$ & + & $735^{a}$ & 26.2 & $0.04^{b}$ & 0.04 \\
\hline Thyme $^{2}, 10$ & + & $476^{b c}$ & 39.5 & $0.06^{b}$ & 0.02 \\
\hline SEM $^{3}$ & & 36.2 & 4.70 & 0.040 & 0.008 \\
\hline \multicolumn{6}{|c|}{$\begin{array}{l}\text { a,b,c,d }- \text { means in columns with different superscripts differ significantly } \\
\text { at } p<0,05 ;{ }^{1} \text { diclazuril administered at dose of } 1 \mathrm{mg} \cdot \mathrm{kg}^{-1} \text { feed; }{ }^{2} \\
\text { herbal extracts administered at dose of } 750 \mathrm{mg} \cdot \mathrm{kg}^{-1} \text { feed; } \\
{ }^{2} \text { SEM - standard error of mean; }{ }^{4} \text { challenge with } 190000 \text { of sporulated } \\
\text { oocysts of mixture of } E \text {. acervulina. E. tenella, E. maxima and } E \text {. } \\
\text { necatrix at } 12 \text { day of age }\end{array}$} \\
\hline
\end{tabular}

\section{Discussion}

The mixed field Eimeria spp. used in the current study induced acute clinical coccidiosis with characteristic signs such as bloody diarrhoea, morbidity, high mortality rate, and affected performance parameters. The detrimental effect of coccidiosis was reflected in significant deterioration in performance indices observed at $21 \mathrm{~d}$ of age in all infected groups, however, the performance of chickens fed the unsupplemented diet was the most affected. The $36 \%$ reduction in BWG in this group was a result of lower FI, disruption of intestinal integrity as an absorptive membrane, and thus much worse efficiency of nutrient assimilation and feed utilization, that are common effects of coccidiosis (Williams, 2005). Worse performance parameters in this group were also noticed in the second and overall experimental periods.

The tested herbal extracts significantly alleviated the detrimental effect of the infection and led to obtaining BWG, FI and FCR values in the second and overall rearing period comparable to those recorded in the coccidiostat-supplemented and uninfected group; however, a limited beneficial effect of most of extracts on performance and mortality rate in the first phase of feeding was found. Taking into account this experimental period, only the sage and garlic extracts demonstrated a positive impact on the course of coccidiosis. There were no significant differences in BWG of broilers fed a diet supplemented with coccidiostat or either extract. Moreover, the garlic extract reduced tality to a level 2-fold lower in respect to the infected unsupplemented group and improved feed conversion as effectively as the coccidiostat. Garlic contains a multiple sulphur compounds such as diallylsulphide, diallyldisulphide, dipropylsulphide and allicin, with allicin having the most beneficial health-promoting effect (Kim et al., 2012). In addition to antimicrobial, antitumor, antithrombotic, antiarthritic, hypolipidaemic and hypoglycaemic activities, the antiparasitic properties of garlic have also been reported in respect to Amoeba, Leishmania, Trypanosoma, Cryptosporidium, Hymenolepsis, Aspiculuris and Histomonas (Dkhil et al., 2011; Kim et al., 2012). Some investigations have also confirmed the positive effect of garlic during Eimeria infection in poultry (Kim et al., 2012), rabbits (Toulah and Al-Rawi, 2007), goats (Worku et al., 2009) and mice (Dkhil et al., 2011). Abu-Akkada et al. (2010) recorded no mortalities, increased BWG, and reduced oocyst output in rabbits administered a daily dose of $0.5 \mathrm{~g}$ crude garlic - $\mathrm{kg}^{-1}$ of body weight for 5 days before challenge with Eimeria stiedae, which causes hepatic coccidiosis, whilst mortality in infected controls was $40 \%$. In broiler chickens experimentally infected with Eimeria acervulina, dietary supplementation with garlic metabolites, propyl thiosulphinate and propyl tiosulphinate oxide, increased BWG, reduced oocyst excretion and enhanced immunity by increasing the profilin antibody response (Kim et al., 2012). Those substances used in in vitro assays directly killed the sporozoites of E. acervulina and stimulated spleen cell proliferation and, according to the authors (Kim et al., 2012), this could be the mechanism of in vivo activity resulting in higher BWG and lowered oocyst shedding. In the present paper, however, no positive effect of garlic extract on faecal oocyst excretion was noted.

Based on the results obtained in the second experimental period, it can be concluded that the addition of each of the tested extracts significantly enhanced compensatory growth, which occurs after the end of a disease process. The OPG numbers on days 7 and 14 post infection observed in these groups, which were several times higher in comparison with the coccidiostat-supplemented group, may suggest the existence of mechanisms other than direct anticoccidial action leading to the positive effects of the extracts on the performance parameters. Although it is desirable, a direct correlation between increased weight gain and reduced faecal oocyst excretion as indicators of host resistance to coccidiosis has not always been observed (Lee et al., 2007). We can speculate on the mechanism of such an effect of herbal extracts in 
the current experiment. The similar, or even greater, number of oocysts recorded on days 7 and 14 post inoculation in almost all of the herbal-supplemented groups as in the unsupplemented and infected group, while maintaining comparable performance may be the effect of reduced damage to enterocytes or promotion of cell renewal, which provided the surface for parasite multiplication. Presumably, the reduced mortality and similar body weight gain in the garlicsupplemented group ( $21 \mathrm{~d}$ of age) in comparison with the coccidiostat-supplemented one may be the result of garlic's ability to stimulate regeneration and improvement in the physiological condition of the intestinal epithelial layer. In the study of Adibmoradi et al. (2006) the addition of garlic meal $(0.5 \%, 1 \%$, $2 \%$ of diet) enhanced villus height and crypt depth and decreased epithelial thickness and goblet cell numbers in the duodenum, jejunum and ileum of birds. Moreover, garlic administration resulted in an increased the villus:crypt ratio in the duodenum, which is an indicator of the digestive capacity and its increase corresponds to an increase in digestion and absorption of nutrients (Adibmoradi et al., 2006). Due to the high effectiveness of herbal extracts in promoting compensatory growth, no significant differences in FI, BWG, or FCR for the entire experimental period were found among the herbal extract-supplemented, coccidiostat-supplemented and uninfected-unsupplemented groups. This effect may be the result of the antioxidant properties of extracts, thus inflammation $-\mathrm{a}$ common result of coccidiosin - could be alleviated, or it may be due to the stabilization of gut microflora, improvement in intestinal integrity and digestive capacity (Windisch et al., 2008). The design and results of the current study are not sufficient to resolve these uncertainties, thus further studies are needed.

The effectiveness in coccidiosis control of some of the herbs tested in the present paper has previously been investigated in other studies. Oregano essential oil administered at dose of $300 \mathrm{mg} \cdot \mathrm{kg}^{-1}$ of diet significantly improved performance, survival rate, lesion score and OPG in chickens infected with E. tenella in comparison with an infected group fed an unsupplemented diet, the improvements, however, were lower than in chickens fed a diet with the coccidiostat, lasalocid (Giannenas et al., 2003). The results of research conducted under an organic rearing system, which forbids the use of coccidiostats, demonstrate that an extract of oregano and vaccine can be an effective part of the prevention of coccidiosis in alternative rearing systems (Waldenstedt, 2003). Feed supplementation with $0.1 \%$ or $0.5 \%$ of an immunopotentiator, Echinacea purpurea, during the first two weeks of life has been demonstrated to significantly improve BWG and reduce total lesion scores in vaccinated broilers, as compared with those given a live vaccination alone (Allen, 2003). Similarly, sage, thyme, and their phenols, such as cineol, borneol, thymol and carvacrol, have also been investigated for their anticoccidial activity (Szabóová et al., 2008).

\section{Conclusions}

In conclusion, the obtained results suggest that the herbal extracts tested in the current study do not prevent coccidiosis induced by highly pathogenic field Eimeria spp., however they do have a beneficial effect on recovery after infection, which was expressed by a favourable impact on compensatory growth and, thus, on the final performance indices without reduction of faecal oocyst excretion.

\section{References}

Abbas R.Z., Iqbal Z., Khan M.N., Zafar M.A., Zia M.A., 2010. Anticoccidial activity of Curcuma longa $L$. in broilers. Braz. Arch. Biol. Technol. 52, 63-67

Abu-Akkada S.S., Oda S.S., Ashmawy K.I., 2010. Garlic and hepatic coccidiosis: prophylaxis or treatment? Trop. Anim. Health Prod. 42, 1337-1343

Adibmoradi M., Navidshad B., Seifdavati J., Royan M., 2006. Effect of dietary garlic meal on histological structure of small intestine in broiler chickens. J. Poultry Sci. 43, 378-383

Allen P.C., 2003. Dietary supplementation with Echinacea and development of immunity to challenge infection with coccidia. Parasitol. Res. 91, 74-78

Anonymous, 2003. Regulation (EC) No 1831/2003 of the European Parliament and of the Council of 22 September 2003 on additives for use in animal nutrition. Off. J. Europ. Union, L. 268, 29-43

Anonymous, 2008. Report from the Commission to the Council and the European Parliament on the use of coccidiostats and histomonostats as feed additives. Brussels, 5.5.2008, $\operatorname{COM}(2008) 233$

Chandrakesan P., Muralidharan K., Kumar V.D., Ponnudurai G., Harikrishnan T.J., Rani K.S.V.N., 2009. Efficacy of a herbal complex against caecal coccidiosis in broiler chickens. Vet. Arh. 79, 199-203

Chapman H.D., 1997. Biochemical, genetic and applied aspects of drug resistance in Eimeria parasites of the fowl. Avian Pathol. 26, 221-244

Dkhil M.A., Abdel-Baki A.S., Wunderlich F., Sies H., Al-Quraishy S., 2011. Anticoccidial and antiinflammatory activity of garlic in murine Eimeria papillata infections. Vet. Parasitol. 175, 66-72

Giannenas I., Florou-Paneri P., Papazahariadou M., Christaki E., Botsoglou N.A., Spais A.B., 2003. Effect of dietary supplementation with oregano essential oil on performance of broilers after experimental infection with Eimeria tenella. Arch. Anim. Nutr. 57, 99-106 
Haq I., Pasha T., Khalique A., 2011. Comparative efficacy of herbal and allopathy drugs against coccidiosis in poultry. Ital. J. Anim. Sci. 10, 14-16

Hashemi S.R., Davoodi H., 2011. Herbal plants and their derivatives as growth and health promoters in animal nutrition. Vet. Res. Commun. 35, 169-180

Kim D.K., Lillehoj H.S., Lee S.H., Lillehoj E.P., Bravo D., 2012. Improved resistance to Eimeria acervulina infection in chickens due to dietary supplementation with garlic metabolites. Brit. J. Nutr. 13, 1-13

Lee S.H., Lillehoj H.S., Dalloul R.A., Park D.W., Hong Y.H., Lin J.J., 2007. Influence of Pediococcus-based probiotic on coccidiosis in broiler chickens. Poultry Sci. 86, 63-66

Lee S.H., Lillehoj H.S., Jang S.I., Kim D.K., Ionescu C., Bravo D., 2010. Effect of dietary Curcuma, Capsicum, and Lentinus on enhancing local immunity against Eimeria acervulina infection. J. Poultry Sci. 47, 87-85

Mazurkiewicz M., 2005. Poultry Diseases (in Polish). Wroclaw University of Environmental and Life Sciences (Editor). Wrockaw (Poland)

Naidoo V., McGaw L.J., Bisschop S.P.R., Duncan N., Eloff J.N., 2008. The value of plant extracts with antioxidant activity in attenuating coccidiosis in broiler chickens. Vet. Parasitol. 153, 214-219

Olejnik M., Szprengier-Juszkiewicz T., Żmudzki J., 2009. Coccidiostats residues in poultry tissues and eggs (in Polish). Med. weter. $65,807-811$

Persia M.E., Young E.L., Utterback P.L., Parsons C.M., 2006. Effects of dietary ingredients and Eimeria acervulina infection on chick performance, apparent metabolizable energy, and amino acid digestibility. Poultry Sci. 85, 48-55

Rahimi S., Teymouri Zadeh Z.T., Karimi Torshizi M.A., Omidbaigi R., Rokni H., 2011. Effect of the three herbal extracts on growth performance, immune system, blood factors and intestinal selected bacterial population in broiler chickens. J. Agr. Sci. Technol. 13, 527-539
Smulikowska S., Rutkowski A. (Editors), 2005. Recommended Allowances and Nutrition Value of Feedstuffs. Poultry Feeding Standards (in Polish). $4^{\text {th }}$ Edition. The Kielanowski Institute of Animal Physiology and Nutrition, PAS, Jabłonna (Poland) and Polish Branch of WPSA

Szabóová R., Lauková A., Chrastinová L., Simonová M., Strompfová V., Haviarová M., Plachá I., Faix Š., Vasilková Z., Chrenková M., Rafay J., 2008. Experimental application of sage in rabbit husbandry. Acta Vet. Brno 77, 581-588

Toulah F.H., Al-Rawi M.M., 2007. Efficacy of garlic extract on hepatic coccidiosis in infected rabbits (Oryctolagus cuniculus): Histological and biochemical studies. J. Egypt Soc. Parasitol. 37, 957-968

Waldenstedt L., 2003. Effect of vaccination against coccidiosis in combination with an antibacterial oregano (Origanum vulgare) compound in organic broiler production. Acta Agr. Scand., Sect. A, Anim. Sci. 53, 101-109

Williams R.B., 2002. Anticoccidial vaccines for broiler chickens: Pathways to success. Avian Pathol. 31, 317-353

Williams R.B., 2005. Intercurrent coccidiosis and necrotic enteritis of chickens: rational, integrated disease management by maintenance of gut integrity. Avian Pathol. 34, 159-180

Windisch W., Schedle K., Plitzner C., Kroismayr A., 2008. Use of phytogenic products as feed additives for swine and poultry. J. Anim. Sci. 86, Suppl. E, E140-E148

Worku M., Franco R., Baldwin K., 2009. Efficacy of garlic as anthelmintic in adult boar goats. Arch. Biol. Sci. 61, 135-140

Youn H.J., Noh J.W., 2001. Screening of the anticoccidial effects of herbs extracts against Eimeria tenella. Vet. Parasitol. 96, 257-263

Ziołecki J., Doruchowski W., 1989. The Method for Evaluation of Poultry Carcass (in Polish). Editor: COBRD, Poznań (Poland) 